\title{
ROUTINE PERIPHERAL BLOOD CHARACTERISTICS, IN PATIENTS WITH COVID-19 - EXPERIENCE FROM STATE COVID HOSPITAL IN SOUTH INDIA
}

\begin{tabular}{l} 
Ramana Kumari \\
Pasam* \\
\hline Sailabala \\
Garikapati
\end{tabular}

B. V. RamaReddy
Department of Pathology, Government Siddhartha Medical College/Government General Hospital, Vijayawada, Andhra Pradesh520008. * Corresponding Author

Department of Pathology, Government Siddhartha Medical College/Government General Hospital, Vijayawada, Andhra Pradesh520008.

Department of Pathology, Government Siddhartha Medical College/Government General Hospital, Vijayawada, Andhra Pradesh520008.

Department of Pathology, Government Siddhartha Medical College/Government General Hospital, Vijayawada, Andhra Pradesh520008.

Department of Pathology, Government Siddhartha Medical RamyaSruthi Gunja College/Government General Hospital, Vijayawada, Andhra Pradesh520008.

ABSTRACT Background: The COVID 19 pandemic is an ongoing pandemic of Corona virus disease 2019. Patients with milder symptoms have good prognosis, but severe and critical patients are difficult to treat and have high mortality rate. Many previous studies show that routine blood parameters help in predicting the progress of infectious diseases.

Aims And Objectives: To analyse the peripheral blood characteristics in patients with COVID 19 and assess the efficacy, in the prognostic terms of COVID 19 patients.

Material And Methods: this is a retrospective study, conducted at a state COVID hospital in South India.

Results: A total of 155 cases of Covid positive patients are presented. According to severity of illness, there are 119 (76.77\%) cases, categorized as mild, 24(15.48\%) cases as moderate and 12 (7.74\%) with severe symptoms.

Conclusion: Periodic follow up of routine peripheral blood parameters, including peripheral blood film examination, help in prediction of severe COVID-19 cases.

\section{KEYWORDS : Routine, peripheral blood, morphology, parameters, Covid-19.}

\section{INTRODUCTION:}

The COVID 19 pandemic is an ongoing pandemic of Corona virus disease 2019, caused by severe acute respiratory syndrome corona virus 2 (SARS $-\mathrm{CoV}-2$ ). ${ }^{1}$

As of 14 June 2020, more than 7.79 million cases of COVID - 19 have been reported in more than 188 countries and territories resulting in more than 4,30,000 deaths; more than 3.71 million people have recovered.

The first case of COVID - 19 in India was reported on $30^{\text {th }}$ January 2020.

As of $14^{\text {th }}$ June 2020, India confirmed a total of $3,20,922$ cases and 9195 deaths. $^{3}$

Even after 6 months of outbreak, COVID 19 lacks specific and effective drugs and vaccine. Patients with milder symptoms have good prognosis, but severe and critical patients are difficult to treat and have high mortality rate.

Hence, it is important to predict the prognosis of the disease.

There are many previous studies on clinical application of routine blood parameters, like neutrophil/lymphocyte ratio, platelet indices etc in predicting the progress of various infectious diseases ${ }^{4,5}$.

In the present study, conducted at state COVID hospital, Vijayawada, Andhra Pradesh, South India, we analysed the clinical features of COVID positive patients with routine peripheral blood characteristics, including the changes in blood cell morphology in peripheral smear.

The aims and objectives of the present study are

1.To analyse the peripheral blood characteristics $(C B C)$ in patients with COVID 19, on admission.

2. To study the morphological features of leucocytes (WBC) in patients with COVID 19.

3. To compare the blood routine parameters between the mild, moderate and severely ill COVID 19 patients.

4. To analyse the efficacy of peripheral blood routine characteristics in the prognostic terms of COVID 19 patients.

\section{MATERIALS AND METHODS:}

The present study is a retrospective study conducted in the department of Pathology, Siddhartha medical college and GGH, State COVID hospital, Andhra Pradesh, South India.

The study period is from march $23^{\text {rd }} 2020$ to June $13^{\text {th }} 2020$.

The institute ethics committee has given approval.

The routine peripheral blood characteristics of all the COVID 19 cases, confirmed by using real time reverse transcriptase polymer chain reaction (RT PCR) assay, are included in the study.

Covid suspects who were tested negative by RT-PCR are excluded from the study. 
A total of 1087 samples were processed during this period, out of which 155 samples were confirmed COVID 19 patients and the remaining 932 were COVID suspects.

All the 155 Covid positive patients are categorized, by the treating physician, into mild, moderate and severe illness , based on the clinical symptoms like fever, respiratory tract symptoms, pneumonia on imaging, shortness of breath, Respiratory rate, $\mathrm{O} 2$ saturation and Chest X-ray.

The data of all the 155 COVID patients is retrieved from the laboratory records, of Department of Clinical Pathology.

\section{RESULT:}

In the present study, routine peripheral blood characteristics of 155 COVID 19 positive cases (confirmed by Real time PCR (RT PCR) assay) are analysed. In the present study patients age ranged from 10 to 89 years. Among them 13 (8.38\%) of the patients were in $3^{\text {rd }}$ decade. $8(5.16 \%)$ patients were in $2^{\text {nd }}$ decade, 6(3.87\%) patients were in $4^{\text {th }}$ decade, 20 (12.90) patients were in $5^{\text {th }}$ decade, $60(38.70)$ patients were in $6^{\text {th }}$ decade, $30(19.35)$ patients were in $7^{\text {th }}$ decade, $13(8.38 \%)$ are of $8^{\text {th }}$ decade and $5(3.22 \%)$ were in $9^{\text {th }}$ decade. Table 1

Table 1: Showing Age Distribution Of 155 Covid Positive Patients.

\begin{tabular}{|l|l|l|}
\hline Age (in years) & No. of cases & Percentage \\
\hline $0-9$ & 0 & 0 \\
\hline $10-19$ & 08 & 5.16 \\
\hline $20-29$ & 13 & 8.38 \\
\hline $30-39$ & 06 & 3.87 \\
\hline $40-49$ & 20 & 12.90 \\
\hline $50-59$ & 60 & 38.70 \\
\hline $60-69$ & 30 & 19.35 \\
\hline $70-79$ & 13 & 8.38 \\
\hline $80-89$ & 05 & 3.22 \\
\hline Total & 155 & $100 \%$ \\
\hline
\end{tabular}

There are $85(54.8 \%)$ male patients and $70(45.6 \%)$ female patients, with male to female ratio (M: F) of 1.2:1. Table 2

Table 2 : Showing Gender Distribution Of 155 Covid Positive Patients.

\begin{tabular}{|l|l|l|}
\hline Gender & NO. OF CASES & PERCENTAGE \\
\hline Male & 85 & 54.8 \\
\hline Female & 70 & 45.6 \\
\hline Total & 155 & 100 \\
\hline
\end{tabular}

According to severity of illness, there are 119 (76.77\%) cases, categorized as mild, $24(15.48 \%)$ cases as moderate and 12 $(7.74 \%)$ with severe symptoms. Table 3

Table 3: Showing Distribution Of 155 Covid + Patients, Based On Severity Of Illness.

\begin{tabular}{|l|l|l|}
\hline Severity of illness & No. of cases & Percentage \\
\hline Mild & 119 & 76.77 \\
\hline Moderate & 24 & 15.48 \\
\hline Severe & 12 & 7.74 \\
\hline Total & 155 & 100 \\
\hline
\end{tabular}

Various hematological parameters in 155 Covid positive patients, categorized as mild, moderate and severely ill are shown in Table 4

Table 4: Showing Various Hematological Parameters In 155 Covid Positive Patients, Categorized Ass Mild, Moderate And Severely Ill.

\begin{tabular}{|l|l|l|l|}
\hline Blood profile & Mild & Moderate & Severe \\
\hline $\begin{array}{l}\mathrm{Hb}(\mathrm{g} / \mathrm{dl}) \\
<10\end{array}$ & $\begin{array}{l}19(15.96 \%) \\
>10\end{array}$ & $10(41.66 \%)$ & $08(66.66 \%)$ \\
\hline $\begin{array}{l}\mathrm{WBC}\left({ }^{*} 10^{9} / \mathrm{L}\right) \\
<2\end{array}$ & 0 & 0 & $04(33.33 \%)$ \\
\hline
\end{tabular}

\begin{tabular}{|c|c|c|c|}
\hline $\begin{array}{l}2-4 \\
>4\end{array}$ & $\begin{array}{l}25(21 \%) \\
94(78.99 \%)\end{array}$ & $\begin{array}{l}0 \\
24(100 \%)\end{array}$ & $\begin{array}{l}04(33.33 \%) \\
07(58.33 \%)\end{array}$ \\
\hline $\begin{array}{l}\text { ALC }\left({ }^{*} 10^{9} / \mathrm{L}\right) \\
<0.5 \\
0.5-1.0 \\
>1\end{array}$ & $\begin{array}{l}0 \\
10(8.40 \%) \\
109(91.59 \%) \\
\end{array}$ & $\begin{array}{l}0 \\
08(33.33 \%) \\
16(66.66 \%)\end{array}$ & $\begin{array}{l}04(33.33 \%) \\
04(33.33 \%) \\
04(33.33 \%)\end{array}$ \\
\hline $\begin{array}{l}\operatorname{ANC}\left({ }^{*} 10^{9} / \mathrm{L}\right) \\
<0.5 \\
0.5-1.0 \\
>1\end{array}$ & $\begin{array}{l}0 \\
04(3.36 \%) \\
115(99.13 \%)\end{array}$ & $\begin{array}{l}0 \\
04(16.66 \%) \\
20(83.33 \%)\end{array}$ & $\begin{array}{l}02(16.66 \%) \\
04(33.33 \%) \\
06(50 \%)\end{array}$ \\
\hline $\begin{array}{l}\operatorname{AMC}\left({ }^{*} 10^{9} / \mathrm{L}\right) \\
<0.5 \\
0.5-1.0 \\
>1\end{array}$ & $\begin{array}{l}0 \\
0 \\
119(100 \%)\end{array}$ & $\begin{array}{l}0 \\
02(8.33 \%) \\
22(91.66 \%)\end{array}$ & $\begin{array}{l}0 \\
01(8.33 \%) \\
11(91.66 \%)\end{array}$ \\
\hline $\begin{array}{l}\text { Platelets }\left({ }^{*} 10^{9} / \mathrm{L}\right) \\
<100 \\
100-150 \\
>150\end{array}$ & $\begin{array}{l}10(8.40 \%) \\
18(15.12 \%) \\
82(68.90 \%)\end{array}$ & $\begin{array}{l}06(25 \%) \\
04(16.66 \%) \\
14(58.33 \%) \\
\end{array}$ & $\begin{array}{l}04(33.33 \%) \\
05(41.66 \%) \\
03(25 \%)\end{array}$ \\
\hline
\end{tabular}

\section{DISCUSSION:}

The present study is a retrospective study, done in the Department of Pathology, attached to state COVID hospital, in the coastal districts of Andhra Pradesh, South India, from $23^{\text {rd }}$ March 2020 to $13^{\text {th }}$ June 2020.

The routine peripheral blood characteristics of 155 consecutive Covid positive patients are analysed, to assess the efficacy in predicting the progress of the disease.

The routine blood parameters of 155 Covid positive patients, categorized as mild, moderate and severe illness, are analysed.

In the present study, the age of the patients ranged from 10 to 89 yrs.

Maximum number of patients are in the $6^{\text {th }}$ decade, accounting to $38.7 \%$ (60 cases) and the gender ratio was 1.2:1 (M:F).

All the 155 Covid positive patients are categorized, by the treating physician, into mild, moderate and severe illness , based on the clinical symptoms like fever, respiratory tract symptoms, pneumonia on imaging, shortness of breath, Respiratory rate, O2 saturation and Chest X-ray.

In the present study, maximum number of cases are in mild category, constituting 119 (76.8\%) cases , followed by $24(15.5 \%)$ cases as moderate and $12(7.8 \%)$ cases with severe symptoms.

In the present study, a few severely ill patients are anemic , at the time of admission.

Suyu sun et al also recorded lower $\mathrm{Hb} \%$ in patients with COVID-19.

Anemia could have caused the severity of symptoms. And also increased inflammatory factors may decrease erythropoiesis and also can increase the destruction of RBC.

In the present study, majority of the patients grouped as mild and moderate categories, the total leukocyte counts are within normal limits and in $21 \%$ of patients with moderate symptoms and $40 \%$ of severely ill patients, lower leukocyte counts are observed.

Suyu sun et al ${ }^{6}$ studied 116 COVID patients , including patients with mild, moderate and severe symptoms. In all the groups they recorded lower total leukocyte counts.

In the present study, $58 \%$ of severely ill patients show elevated total leukocyte counts and except 20 cases with mild thrombocytopenia, majority cases did not show decreased 
platelet counts, like in any other viral fevers.

However, we recorded some morphological changes, like giant platelets among the severely ill category.

Wang et al ${ }^{7}$ reported, in some cases thrombosis may lead to platelet consumption and therefore cause thrombocytopenia.

The Absolute Lymphocyte Count(ALC) is within normal limits, in majority (91.6\%) of the patients with mild symptoms.

Some of the cases with moderate symptoms (33\%) and majority of cases with severe symptoms(66.6\%) showed lower ALC.

This finding correlates with other studies in the literature.

COVID-19 infection elicits a severe inflammatory response, which causes redistribution of lymphocytes and hence, peripheral blood lymphocytopenia is observed ${ }^{8}$.

$50 \%$ of the cases with severe symptoms, there were increased neutrophil counts.

Increased neutrophil counts among severely ill patients can explained by superimposed bacterial pneumonia ${ }^{9}$ and sign of cytokine storm.

92\% of severely ill patients showed increased Absolute Monocyte Count.

This finding did not correlate with other studies (Mehta et al), where absolute values of monocytes and lymphocytes were low in the severe ICU group ${ }^{10}$.

Consistently, we recorded decreased eosinophil counts, among all the categories of Covid positive patients, at the time of admission.

This finding correlates with the other studies, who reported that eosinophils significantly decreased in all three groups on admission ${ }^{6}$

Samarsinghe etal ${ }^{11}$ reported that in the acute phase of the lung infection caused by virus, eosinophils accumulate in infected tissues to resist virus infection, resulting in a decrease in eosinophils in peripheral blood. The eosinophil counts start to increase early in mild to moderate cases and was delayed in some cases of severe category. Persistent low eosinophil counts may be the sign of poor outcome ${ }^{12}$. Serial surveillance of eosinophils counts was not be done.

We observed several morphological changes of leukocytes and platelets. Neutrophils showed changes like hypolobated nuclei, elongated nucleoplasm, toxic granulations, cytoplasmic vacuolations and also a characteristic finding of ring nuclei in 4 cases of the severely ill cases (Fig l).

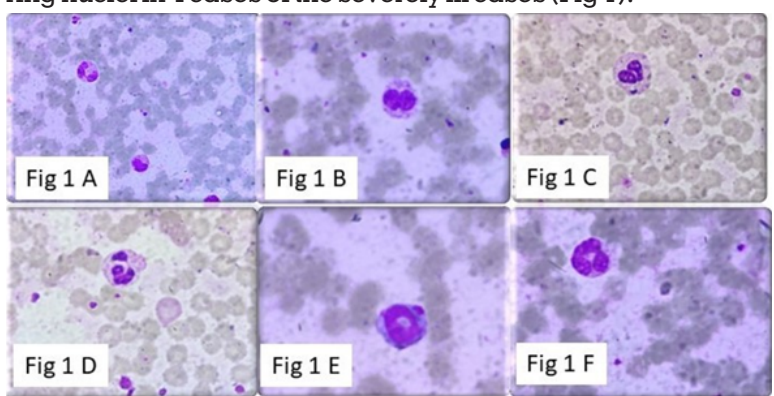

Fig lA \& B: Hypolobated neutrophils with coarse granules in cytoplasm. Fig 1C: Cytoplasmic vacuolations, Fig ID: Elongated nucleoplasm, Fig E \& F: Ring nuclei.

The changes observed in lymphocytes are predominance of granular large lymphocytes (NK cells), similar changes observed in viral infection like irregular nuclear membrane and abundant pale cytoplasm (Fig 2). 2 cases showed nuclear pod formation (Fig 2F).

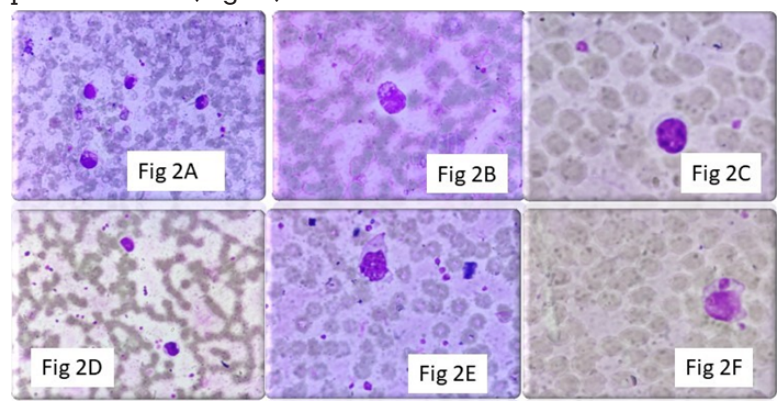

Fig 2A \& B: Large granular lymphocytes(NK cells), Fig 2C: Abundant pale blue cytoplasm, Fig 2D \& E- Round to indented nuclei, Fig 2F- Cytoplasmic pod formation.

Though the platelet counts were within normal limits, in majority of cases, we observed giant platelets in some of the severely ill cases (Fig 3A,B).
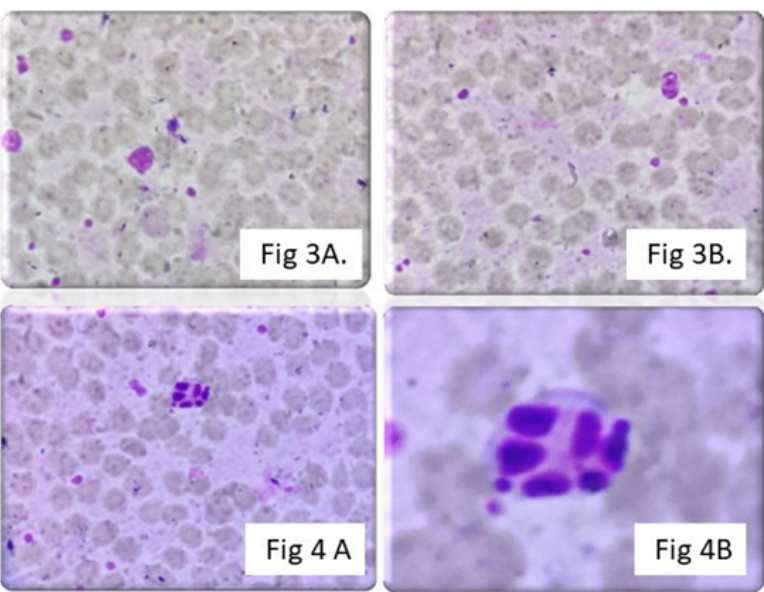

Fig 3A\&B: show Giant platelets, Fig 4A \& B: show Apoptotic cell.

Degenerating cells-Apoptotic cell(Fig 4A,B) was observed in 2 cases.

Similar morphological changes were observed by Aminder singh et $\mathrm{al}^{14}$.

Covid 19 pandemic in Malaria endemic region.

In the present study, we observed Plasmodium vivax trophozoites, in cases of Covid suspects, who were negative for Covid 19 on RT PCR assay.

Covid 19 pandemic in Malaria endemic regions is an important finding and there is need for enhanced sensitization on the potential for Malaria/COVID-19 coinfection and to avoid misclassification of disease symptoms. Malaria shares the highly recognizable symptoms with COVID-19 such as: fever, difficulty in breathing, fatigue and headaches of acute onset. Thus, a malaria case may be misclassified as COVID-19, when symptoms alone are used to define a case, during emergency. Untreated malaria can cause further community infections. Some patients may be lost if they are declared COVID-19 negative while in fact they may be malaria positive. This can be overcome by reorganizing the laboratories to perform rapid malaria test, where COVID testing is being done and should be supplied with malaria test kits ${ }^{15,16}$.

\section{CONCLUSIONS:}

- Majority of the cases are with mild and moderate 
symptoms. Severely ill cases constitute only $7.7 \%$.

- Gender ratio is 1.2:1(M:F).

- Anemia is observed in a few cases of severely ill category, at the time of admission.

- The total leukocyte counts are lower in $40 \%$ of severely ill cases where as $58 \%$ of severely ill cases show increased total leukocyte counts.

- Mild thrombocytopenia is observed in $20 \%$ of cases.

- Absolute lymphocyte count is low in $66.6 \%$ of severely ill and $33 \%$ of moderately ill cases.

- $50 \%$ of all severely ill cases show increased absolute neutrophils counts.

- $92 \%$ of severely ill cases show high absolute monocyte count.

- Morphological changes like ring nuclei in neutrophils, cytoplasmic pod formation and apoptotic bodies in lymphocytes and giant platelets are characteristic findings observed.

- Trophozoites of plasmodium vivax observed in Covid suspects ,remind the need for enhanced sensitization on the potential of Covid-19/malaria co-infection.

\section{Acknowledgements: None}

\section{Funding: None}

\section{Competing Interests: None}

\section{REFERENCES:}

1. Naming the corona virus disease (COVID 19) and the virus that cases it. "World health organisation".

2. COVID 19 Dashboard by the ceafer systems science and engineering (CSSE) at John hoppings university.

3. Ministry of health and family welfare/GOT mohfw.gov.in 3) retrieved $14^{\text {th }}$ June 2020.

4. Jan $\mathrm{Hc}, \mathrm{Wh}$, Yang, $\mathrm{Ch}, \mathrm{Ou}, \mathrm{Combination}$ of the preoperative systemic immune inflammation index and monocyte-lymphocyte ratio as a novel prognostic factor in patients with upper tract urothelial carcinoma. Ann.Surgical Oncol.26(2019)669-684.

5. P.RamanaKumari, G.Sampoorna et al. A comparative study of platelet indices, in cases of fever, sepsis leading to multiorgan dysfunction and control group, at a tertiary care hospital using automated hematology analyser, sysmex Xn 1000. IOSR JDMS, 16.12(2017):27-33

6. SuyuSun, Xuejiao Cá, Huaguo Wang et al. Abnormalities of peripheral blood system in patients with COVID-19 in Wenzhou,China. Clinica Chimica Acta 507(2020) 174-180.

7. Z.Wang, B.Yang, Q. Li et al., Clinical features of 69 cases with corona virus disease 2019 in Wuhan, China, Clin. Infect. Dis.: Off. Publ. Infect. Dis. Soc. Am.(2020).

8. Xh. Yao, Li Ty, He Zc, et al., A pathological report of three COVID-19 cases by minimally invasive autopsies, Zhonghua bing li xue za zhi $=$ Chinese J. Pathol. 49(2020) E009,

9. X. Li, L. Wang, S. Yan, et al., Clinical characteristics of 25 death cases with COVID-19: a retrospective review of medical records in a single medical center, Wuhan,China, Int. J. Infect. Dis: IJID: Off. Publ. Int. Soc. Infect. Dis. (2020).

10. P.Mehta, D.F. Mcauley, M. Brown, et al., COVID-19: consider cytokine storm syndromes and immunosuppression, Lancet (London, England) (2020).

11. Samarasinghe Ae, Woolard Sn, Boyd KI et al. The immune profile associated with acute allergic asthma accerlates clearance of influenza virus, Immunol. Cell Biol.92 (2014) 449-459

12. F.Liu, A.Xu, Y.Zhang et al. Patients of COVID-19may benefit from sustained lopinavir-combined regimen and increase of eosinophil may predict the outcome of COVID-19 progression. Int J Infect, Dis. : IJID: Off. Publ. Int. Soc, Infect.Dis.(2020)

13. Wong RSM, Wu A, To KF et al. Hematological manifestations in patients with severe acute respiratory syndrome: retrospective analysis. BMJ. 2003; 326: 1358-1362.

14. Singh A, Sood N, Narang V et al. Morphology of COVID-19 affected cells in peripheral blood film. BMJ case Rep 2020: 13:e236117 doi:10.1136/bcr-2020236117.

15. P.Chanda-Kapata et al. COVID -19 and malaria: A symptom screening challenge for malaria endemic countries. International Journal of Infectious diseases 94(2020) 151-153.

16. Ngyuen T, Duong Bang D, Wolff A. 2019 novel corona virus disease(COVID19): paving road for rapid detection and point- of -care diagnostics. Micromachines (Basel) 2020; 11 (3) E306. 